\title{
Longterm Safety of Patients Receiving Rituximab in Rheumatoid Arthritis Clinical Trials
}

\author{
RONALD F. van VOLLENHOVEN, PAUL EMERY, CLIFTON O. BINGHAM III, EDWARD C. KEYSTONE, \\ ROY FLEISCHMANN, DANIEL E. FURST, KATHERINE MACEY, MARIANNE SWEETSER, ARIELLA KELMAN, \\ and RAVI RAO
}

\begin{abstract}
Objective. To evaluate the longterm safety of rituximab in clinical trials in patients with rheumatoid arthritis (RA).

Methods. Pooled analysis of safety data, including adverse events (AE) and infections, from patients treated with rituximab in combination with methotrexate in a global clinical trial program.

Results. A total of 2578 patients with RA received at least 1 course of rituximab. Safety analyses were based on 5013 patient-years of rituximab exposure. The most frequent AE was infusion-related reactions ( $25 \%$ of patients during the first infusion of Course 1 ). Less than $1 \%$ of infusion-related reactions were considered serious. Rates of $\mathrm{AE}$ and serious AE (SAE; 17.85 events/100 patient-yrs, 95\% CI 16.72, 19.06) were stable following each course. The overall serious infection rate was $4.31 / 100$ patient-years $(95 \%$ CI $3.77,4.92)$. Infections and serious infections over time remained stable across 5 courses at 4-6 events/100 patient-years. Compared with other patients with RA and with the general US population, there was no increased risk of malignancy.

Conclusion. In this longterm safety update in RA clinical trial patients, rituximab remained well tolerated over multiple courses. SAE and infections remained stable over time and by treatment course. (First Release Feb 1 2010; J Rheumatol 2010;37:558-67; doi:10.3899/jrheum.090856)
\end{abstract}

\section{Key Indexing Terms:} RITUXIMAB

The goal of achieving effective treatment options for patients with rheumatoid arthritis (RA) has led to the development of biologic therapies that have improved our ability to control the signs and symptoms of RA, prevent structural joint damage, and attenuate functional losses ${ }^{1-4}$. Because RA is a chronic disease, therapies are administered over prolonged periods, a situation that requires continued vigilance of safety events.

Tumor necrosis factor (TNF) inhibitors have demonstrated acceptable safety profiles in longterm followup programs, but concerns have been expressed about serious

From Karolinska University Hospital, Stockholm, Sweden; Leeds General Infirmary, Leeds; Roche Products Ltd., Welwyn Garden City, UK; Johns Hopkins University, Baltimore, Maryland; University of Texas

Southwestern Medical Center at Dallas, Dallas, Texas; University of California at Los Angeles, Los Angeles; Biogen Idec Inc., Cambridge, Massachusetts; Genentech Inc., South San Francisco, California, USA, and University of Toronto, Toronto, Ontario, Canada.

R.F. van Vollenhoven, $M D, P h D$, Karolinska University Hospital; P. Emery, MD, Leeds General Infirmary; C.O. Bingham III, MD, Johns Hopkins University; E.C. Keystone, MD, FRCP, University of Toronto; R. Fleischmann, MD, University of Texas Southwestern Medical Center at Dallas; D.E. Furst, MD, University of California at Los Angeles; K. Macey, MSc; R. Rao, MA, PhD, MRCP, Roche Products Ltd.; M. Sweetser, MD, Biogen Idec Inc.; A. Kelman, MD, Genentech Inc. Address correspondence to Dr. R.F. van Vollenhoven, Rheumatology Unit, The Karolinska Institute, D2-1, SE-17176, Stockholm, Sweden.

E-mail: ronald.van.vollenhoven@ki.se

Full Release Article. For details see Reprints/Permissions at jrheum.org Accepted for publication October 21, 2009. infections, aggravation of congestive heart failure, and malignancies ${ }^{1-3,5}$. Because of the immunomodulatory effects of RA therapies, it has become clear that specific safety adverse events (AE) should be monitored, especially more common infections, as well as less common events such as tuberculosis and lymphoma ${ }^{6}$. Moreover, RA itself has also been shown to increase the risk of serious infection, certain malignancies, and cardiovascular disease, either by the disease process or as a result of therapy ${ }^{7-9}$.

Rituximab is approved for the treatment of non-Hodgkin's lymphoma and $\mathrm{RA}^{10-13}$. Rituximab acts by binding to the CD20 antigen, leading to depletion of CD20-positive B cells in the blood and other compartments. CD20 is not expressed on stem cells ${ }^{14}$ (allowing B cell recovery after treatment) or on plasma cells. The safety and efficacy of rituximab in the treatment of RA has been reported in randomized placebo-controlled trials of 6-12 months' duration, while open-label extension studies have analyzed safety and efficacy results over multiple courses of rituximab ${ }^{11-13,15}$.

Our purpose is to describe the safety profile of patients with RA who were treated with rituximab in clinical trials. Because of the effect of rituximab on B cells, we evaluated specific AE that were possibly attributable to B cell depletion, in addition to safety events of special interest in patients with RA. This analysis involves a larger number of rituximab-treated patients than previously reported, followed for multiple courses. These patients had a previous inadequate response to TNF inhibitors and/or methotrexate (MTX). 


\section{MATERIALS AND METHODS}

Patients and studies. For longterm safety assessments, analyses included pooled safety data from patients with RA who were treated with rituximab in combination with MTX from an international clinical trial program, and patients who participated in 9 clinical trials, including 2 open-label extension studies (Figure 1A) ${ }^{11,12,16-20}$. For 6-month placebo-controlled analyses, events were pooled from studies with a 6-month placebo-controlled treatment period (IIa, DANCER, REFLEX, and SERENE).

Prior to each infusion of rituximab, most patients received methylprednisolone $100 \mathrm{mg}$ intravenously (IV), and in some cases received additional oral corticosteroids, depending on the specific study. Most patients also received acetaminophen and an antihistamine prior to each infusion. The safety analysis population included all patients who received any dose of rituximab. A single course of rituximab was defined as IV infusions of either $2 \times 500 \mathrm{mg}$ or $2 \times 1000 \mathrm{mg}$ given 2 weeks apart. Patients were re-treated with rituximab about every 6 months in some studies (re-treatment if DAS28 $\geq 2.6$; SERENE, MIRROR, SUNRISE) while in other studies time to re-treatment was more variable (IIa, DANCER, REFLEX, SIERRA).

Safety assessments. Safety monitoring included the collection of all AE and serious AE (SAE), regardless of cause. All AE were graded according to the Common Terminology Criteria for AE, version 3, or per reported protocols $^{11,12,15}$. In all studies, patients were followed for the duration of the study period and then for at least 1 year after completion or withdrawal, or longer for patients whose peripheral CD19-positive B cells were below the lower limit of normal (LLN) or baseline. SAE were defined as events that were fatal, immediately life-threatening, required inpatient hospitalization or prolongation of an existing hospitalization, medically significant, or required intervention to prevent one of the above outcomes. For classification purposes, original terms were assigned preferred terms, using the Medical Dictionary for Regulatory Activities (MedDRA), version 10.1.

Serious infection events (SIE) were defined as SAE infections and infections treated with IV antibiotics. Potential opportunistic infections were evaluated using a glossary of MedDRA terms. An infusion-related reaction (IRR) was identified by a glossary of MedDRA terms for AE occurring during or within 24 hours of an infusion. Malignancies were identified using standard MedDRA Query terms for malignancy.

Event rates were calculated as events per 100 patient-years (pt-yrs) of rituximab exposure. Overall event rates were based on all exposed patients

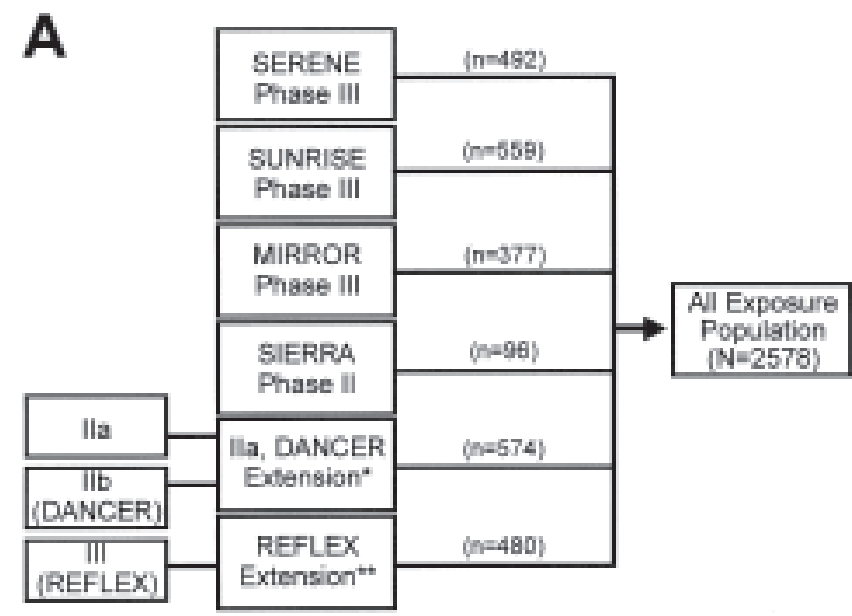

Figure 1A. Patients pooled from the rituximab RA clinical trial program had previously participated in 1 of 9 studies. Studies included SERENE, SUNRISE, MIRROR, REFLEX, SIERRA, DANCER, and IIa, as well as 2 open-label extension studies. *Patients originally receiving rituximab in Phase IIa and IIb (DANCER) trials and then in open-label extension study. **Patients originally receiving rituximab in Phase III (REFLEX) trial and then in open-label extension study. and all reported events, regardless of number of courses received, while per-course rates were limited to the first 5 courses.

Immunoglobulin levels (isotypes $\operatorname{IgA}, \operatorname{IgG}, \operatorname{IgM}$ ) and human antichimeric antibodies against rituximab (HACA) were assessed periodically, on average every 8 to 12 weeks, depending on the trial. Multivariate Cox regression analyses were performed to identify independent baseline predictors of serious infection and separately to identify predictors of having sustained low IgG levels (defined as IgG below the laboratory LLN on at least 2 consecutive occasions for at least 1 year). Potential predictors included baseline steroid use, rheumatoid factor seropositivity, RA duration, age, prior use of TNF inhibitor(s), and baseline immunoglobulin levels.

\section{RESULTS}

Disposition and duration of exposure. As of November 2007, 2578 patients had received rituximab, providing $5013.5 \mathrm{pt}-\mathrm{yrs}$ of observation in the clinical trials. A total of 2244 patients had $\geq 1$ year of followup, 851 patients had $\geq$ 2 years, 720 patients had $\geq 3$ years, 317 patients had $\geq 4$ years, and 97 patients had $\geq 5$ years. All 2578 patients received at least 1 treatment course with 1890, 1043, 425, and 133 patients having received $\geq 2, \geq 3, \geq 4$, and $\geq 5$ courses, respectively (Figure 1B). Few patients received $>5$ courses, with 50, 26, 9, 4, and 1 having received $\geq 6, \geq 7, \geq$ $8, \geq 9$, and 10 courses, respectively. Patients in the SUNRISE and SIERRA trials were limited to treatment with 1 or 2 courses of rituximab treatment, by protocol design. Patients who neither withdrew nor received a subsequent course before the data cutoff were considered remaining "on-study."

A total of 123 patients $(5 \%)$ who received rituximab withdrew because of $\mathrm{AE}$, including 57 (2\%) because of SAE. The most common AE leading to withdrawal, excluding arthritis-related events, were IRR (29 events), malignancies (19 events), infections (15 events), and cardiac disorders (6 events). All other AE leading to withdrawal were isolated cases with no apparent pattern.

Baseline characteristics of patients. The majority were female (80\%), with mean age 53 years, and disease duration 10 years (Table 1). Prior to rituximab treatment, patients had received, on average, 3 previous biologic or nonbiologic disease-modifying antirheumatic drugs (DMARD; excluding MTX), with $53 \%$ of patients previously treated with TNF inhibitor(s).

Overall and SAE. The overall rate of AE was 359.6 events per 100 pt-yrs (95\% CI 354.4, 364.9). Overall AE rates were highest for Course 1, declining for Course 2, and then remaining stable for further courses (Table 2, Figure 2). The higher rate with Course 1 was largely due to nonserious IRR during the first infusion of Course 1 . The most commonly reported AE were IRR, particularly with Course 1 (25\% of patients during the first infusion). Other AE that occurred in $\geq 10 \%$ of patients (but not including RA exacerbation) included upper respiratory tract infections (19\%), nasopharyngitis $(13 \%)$, urinary tract infection $(11 \%)$, and bronchitis (10\%). Eighty-three percent of AE were Grade 
B

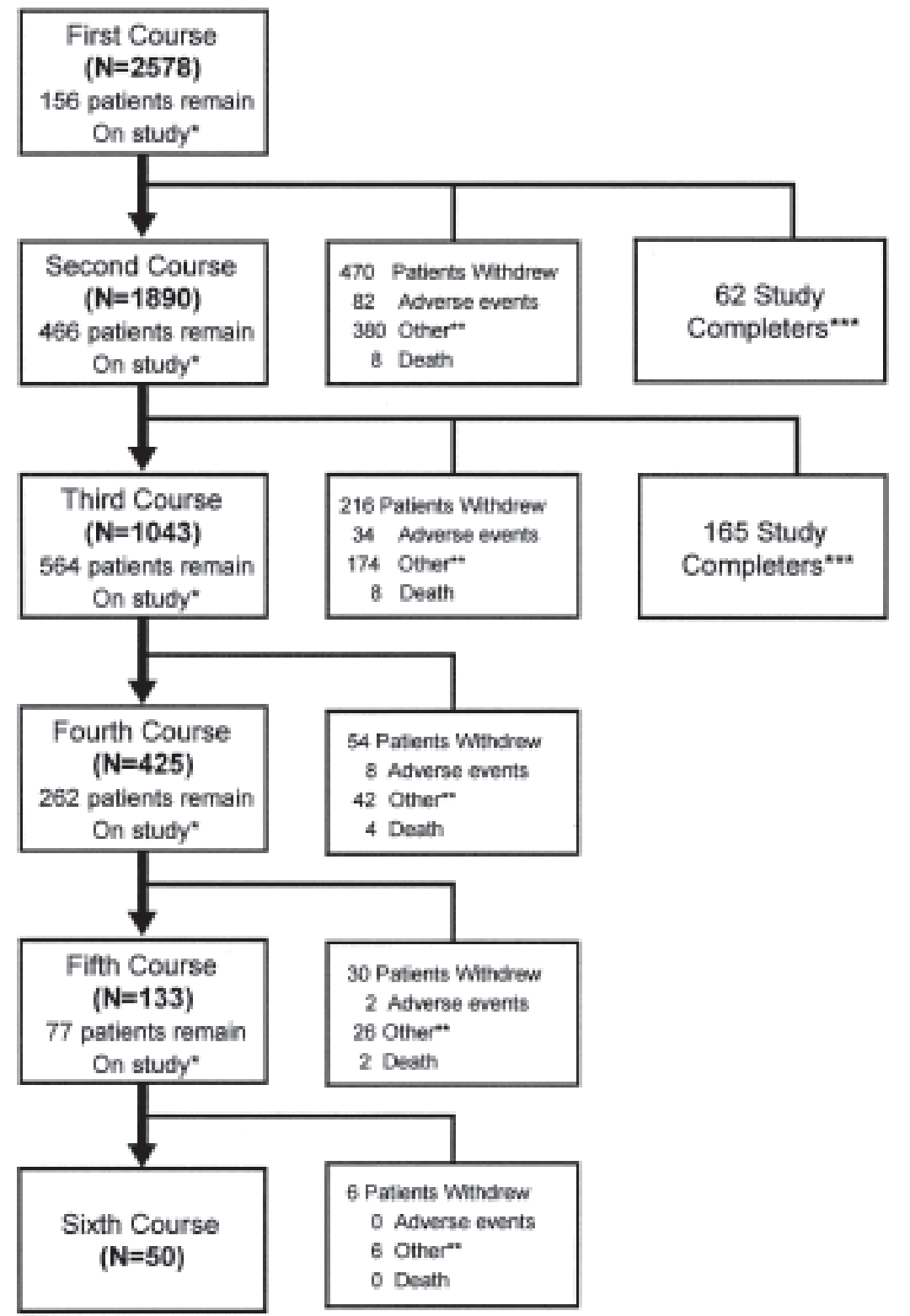

Figure $1 B$. Disposition of patients over treatment courses 1 to 5 . Patients who received a re-treatment course are indicated. Withdrawals due to adverse events (AE), deaths, and reasons other than AE, are shown. "Other" includes insufficient therapeutic response, failure to return, violation of selection criteria at entry, other protocol violation, refused treatment/did not cooperate, withdrew consent, administrative/other, lost to followup, physician's decision to withdraw, and pregnancy. After courses 1 and 2, study completers from SUNRISE and SIERRA, who were not offered additional courses of rituximab, are shown. *On study but without further infusions at time of data cut. **Withdrawal for reasons other than AE. ***Patients completed their course and were not offered additional re-treatment courses.

1-2 (mild to moderate), $7 \%$ of AE were Grade 3, and $0.4 \%$ of AE were Grade 4.

The overall SAE rate was 17.85 events/100 pt-yrs $(95 \%$ CI 16.72, 19.06). The rate of SAE within sequential 6-month intervals up to a total duration of 5 years and irrespective of the number of rituximab courses was stable (Figure 2B).
Similarly, the rate of SAE within each treatment course remained stable across courses (Table 2). The most common SAE, excluding arthritis-related events such as joint replacement surgery and RA exacerbation, were pneumonia $(\mathrm{n}=27,1 \%)$, fall $(\mathrm{n}=25 ; \sim 1 \%)$, and myocardial infarction $(\mathrm{MI} ; \mathrm{n}=23,0.9 \%)$. The rate of MI was 0.56 per 100 pt-yrs. 
Table 1. Baseline patient characteristics: the observed values of the original baseline, i.e., the screening or baseline visit in the patient's original study.

\begin{tabular}{lc}
\hline & $\begin{array}{c}\text { All Exposure Population, } \\
\mathrm{n}=2578\end{array}$ \\
Characteristics & $52.5(11.8)$ \\
\hline Mean age (SD), yrs & $2070(80.3)$ \\
Female, no. (\%) & $2057(79.8)$ \\
Race, no. (\%) & $114(4.4)$ \\
White & $319(12.4)$ \\
Black & $88(3.4)$ \\
Hispanic & $1956(75.9)$ \\
Other & $10.1(8.3)$ \\
Rheumatoid factor-positive, no. (\%) & \\
Mean RA disease duration (SD), yrs & $2.6(2.0)$ \\
$\quad$ (3 patients not included) & $0.8(1.0)$ \\
Mean no. (SD) previous biologic and nonbiologic & 53 \\
DMARD (excluding MTX) & 36 \\
Mean no. (SD) previous biologic DMARD & Patients \\
Previously treated with TNF inhibitor, \% & \\
Baseline use of concomitant corticosteroids, \% & $6.65(1.0)^{* *}$ \\
\hline Baseline Disease Activity* & $20.4(11.2)$ \\
\hline Mean DAS28-ESR (SD) & $31.6(15.5)$ \\
Mean SJC (66 joints) (SD) & \\
Mean TJC (68 joints) (SD) & \\
\hline * $\mathrm{n}=1923$ patients; data for 655 pateints from SUNRISE and SIERRA \\
studies were not included. ** $\mathrm{n}=1920$ patients. DMARD: disease-modi- \\
fying antirheumatic drug; MTX: methotrexate; TNF: tumor necrosis fac- \\
tor; DAS28: disease activity score in 28 joints; ESR: erythrocyte sedimen- \\
tation rate; SJC: swollen joint count; TJC: tender joint count. \\
\hline
\end{tabular}

The rates did not increase over repeated courses of rituximab. The majority of these patients had 1 or more risk factors for MI, including prior MI, ischemic heart disease, coronary artery disease, hypertension, diabetes, or hypercholesterolemia. Congestive heart failure SAE were reported in 3 patients. During the 6-month placebo-controlled periods, rates of cardiovascular SAE were similar between the placebo and rituximab groups $(1.2 \%$ and $1.3 \%$, respectively; Table 3).

Thirty deaths (0.6 per 100 pt-yrs) were reported. Causes and time to death were variable, without a discernible pattern, and there were no infusion-related deaths. The standardized mortality ratio (SMR) compared to the general US population, adjusting for age and sex, was $0.83(95 \% \mathrm{CI}$ $0.56,1.18)^{21}$.

IRR were experienced by 915 patients (36\%), with the incidence being highest during the first infusion of Course 1 (25\%). The incidence of IRR in all subsequent courses was reduced (Figure 2A). The most common IRR symptoms were headache, pruritus, throat irritation, flushing, rash (typically described as urticaria and erythema), hypertension, and pyrexia. Most reactions were mild to moderate in severity. The proportion of patients with IRR that required slowing, stopping, or interruption of infusion was the highest during Course $1(9 \%)$, and subsequently declined to $5 \%$, $3 \%, 2 \%$, and $0 \%$ for Courses 2 to 5 , respectively. Overall, < $1 \%$ of patients withdrew because of IRR. Of the IRR reported, 15 events in 14 patients $(0.5 \%)$ were SAE. These included anaphylactic reactions, edema, rash, headache, throat irri-

Table 2. Summary of adverse events (AE) by treatment course.

\begin{tabular}{|c|c|c|c|c|c|}
\hline & $\begin{array}{c}\text { Course } 1 \\
\mathrm{n}=2578 \\
\text { No. }(\%)\end{array}$ & $\begin{array}{c}\text { Course } 2, \\
\mathrm{n}=1890 \\
\text { No. }(\%)\end{array}$ & $\begin{array}{c}\text { Course } 3 \\
\mathrm{n}=1043 \\
\text { No. }(\%)\end{array}$ & $\begin{array}{c}\text { Course } 4, \\
\mathrm{n}=425, \\
\text { No. }(\%)\end{array}$ & $\begin{array}{c}\text { Course } 5, \\
\mathrm{n}=133 \\
\text { No. }(\%)\end{array}$ \\
\hline Total Patient-years & 2456.25 & 1573.60 & 640.83 & 237.52 & 73.25 \\
\hline Patients with an $\mathrm{AE}$ & $2145(83)$ & $1391(74)$ & $675(65)$ & $248(58)$ & $81(61)$ \\
\hline Total no. of AE & 9606 & 5184 & 2111 & 768 & 226 \\
\hline AE/100 pt-yrs & 391.08 & 329.44 & 329.42 & 323.33 & 308.52 \\
\hline $95 \% \mathrm{CI}$ & $383.34,398.98$ & $320.59,338.53$ & $315.66,343.77$ & $301.26,347.03$ & $270.80,351.48$ \\
\hline Patients with an SAE & $320(12)$ & $197(10)$ & $79(8)$ & $21(5)$ & $11(8)$ \\
\hline No. of SAE & 457 & 282 & 114 & 23 & 12 \\
\hline $\mathrm{SAE} / 100 \mathrm{pt}-\mathrm{yrs}$ & 18.61 & 17.92 & 17.79 & 9.68 & 16.38 \\
\hline $95 \% \mathrm{CI}$ & $16.98,20.39$ & $15.95,20.14$ & $14.81,21.37$ & $6.43,14.57$ & $9.30,28.85$ \\
\hline Patients with an infection & $1210(47)$ & $820(43)$ & $379(36)$ & $146(34)$ & $43(32)$ \\
\hline No. of infections & 2416 & 1498 & 648 & 236 & 65 \\
\hline Infections/100 pt-yrs & 98.36 & 95.20 & 101.12 & 99.36 & 88.73 \\
\hline $95 \% \mathrm{CI}$ & $94.52,102.36$ & $90.50,100.14$ & $93.63,109.21$ & $87.46,112.88$ & $69.58,113.15$ \\
\hline $\begin{array}{l}\text { Patients with a serious } \\
\text { infection }\end{array}$ & $86(3)$ & $53(3)$ & $26(2)$ & $8(2)$ & $4(3)$ \\
\hline No. of serious infections & 110 & 60 & 31 & 9 & 5 \\
\hline \multicolumn{6}{|l|}{ Serious infections/ } \\
\hline 100 pt-yrs & 4.48 & 3.81 & 4.84 & 3.79 & 6.83 \\
\hline $95 \% \mathrm{CI}$ & $3.72,5.40$ & $2.96,4.91$ & $3.40,6.88$ & $1.97,7.28$ & $2.84,16.40$ \\
\hline $\begin{array}{l}\text { Patients who withdrew } \\
\text { due to } \mathrm{AE}\end{array}$ & $78(3.2)$ & $36(1.8)$ & $6(<1)$ & $2(<1)$ & 0 \\
\hline
\end{tabular}

SAE: serious adverse event. 

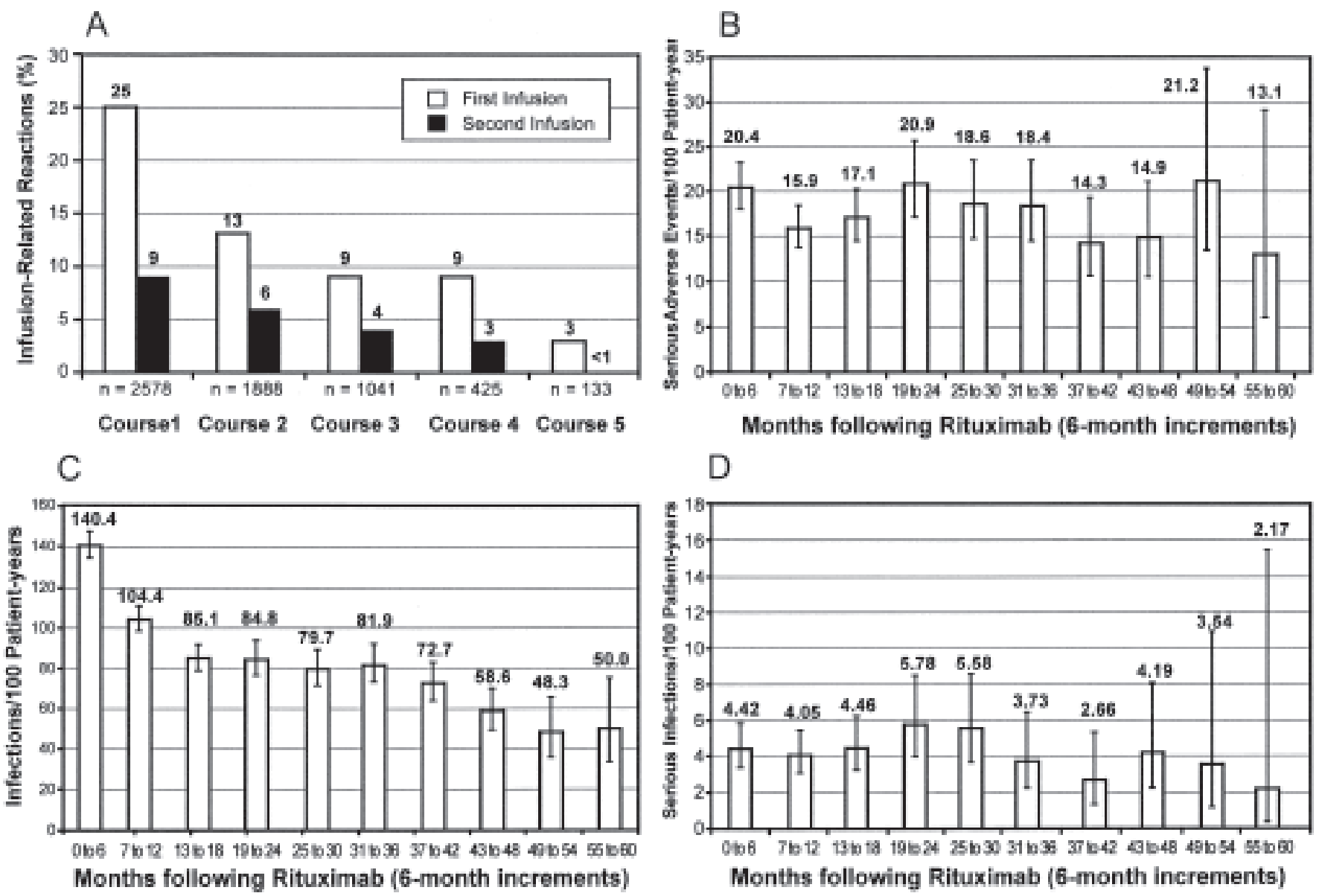

Figure 2. A. Infusion-related reactions across 5 treatment courses. B. Serious adverse events. C. Infection rates. D. Serious infection rates.

tation, dyspnea, chest pain, and blood pressure changes. Of the SAE IRR, 8 occurred during the first infusion of Course 1, 2 during the second infusion of Course 1, 3 during the first infusion of Course 2,1 during the second infusion of Course 2, and 1 during the first infusion of Course 4.

Immunogenicity. Eleven percent (273/2578) of patients had a HACA-positive titer on at least 1 visit. The proportion of patients with overall IRR upon re-treatment was similar between patients who were previously HACA-positive and patients who were previously HACA-negative, with $15 \%$ (24/157) of patients who were previously HACA-positive and $17 \%(286 / 1733)$ of patients who were previously HACA-negative experiencing IRR during Course 2. Two patients who were HACA-positive experienced serious infusion reactions with re-treatment. One of these patients tested HACA-positive prior to infusion and the other subsequently. This compares with a total of 14 patients with serious infusion reactions $(0.5 \%)$ in the entire population, regardless of HACA positivity.

Infections. A total of $1663(65 \%)$ patients experienced infections with a rate of 97.7 per 100 pt-yrs (95\% CI 95.0, 100.5). During the 6-month placebo-controlled periods, rates of overall infections were similar between the placebo and rituximab groups (39\% and 40\%, respectively; Table 3).

SIE were reported in 170 patients (7\%), an overall serious infection rate of 4.31 per 100 pt-yrs (95\% CI 3.77, 4.92). The most common serious infection was pneumonia, affecting 27 patients (1\%). All other serious infections were reported in $<1 \%$ of patients, the most common of which were cellulitis (15 patients) and urinary tract infection (13 patients). During the 6-month placebo-controlled periods, rates of serious infections were similar between the placebo and rituximab groups (1.6\% and $1.7 \%$, respectively; Table 3 ).

The rates of both overall and serious infections were stable over time and also between courses (Table 2, Figures 2C and 2D), with a higher rate of overall but not serious infection observed during the initial 6 months of treatment. A higher point estimate was seen for serious infections during Course 5, but with a wide CI.

Opportunistic infections and infections of special interest. There were no cases of tuberculosis, disseminated fungal infections, or other serious opportunistic infections during the analysis period. After the analysis data cutoff date, 1 case of progressive multifocal leukoencephalopathy (PML) Personal non-commercial use only. The Journal of Rheumatology Copyright (c) 2010. All rights reserved. 
Table 3. Adverse events occurring during the 6-month placebo-controlled period. For the placebo + methotrexate group, data pooled from trials: IIa, DANCER, REFLEX, and SERENE studies. Multiple occurrences of the same adverse event in 1 individual counted only once.

\begin{tabular}{|c|c|c|}
\hline & $\begin{array}{c}\text { Placebo + } \\
\text { methotrexate } \\
(n=570)\end{array}$ & $\begin{array}{l}\text { Rituximab + } \\
\text { methotrexate } \\
\quad(n=877)\end{array}$ \\
\hline Total patients $(\%)$ with cardiovascular SAE & $7(1.2)$ & $11(1.3)$ \\
\hline Coronary artery disease & $2(0.4)$ & $2(0.2)$ \\
\hline Myocardial infarction & $1(0.2)$ & $3(0.3)$ \\
\hline Angina unstable & $1(0.2)$ & $1(0.1)$ \\
\hline Deep vein thrombosis & $1(0.2)$ & $1(0.1)$ \\
\hline Angina pectoris & $1(0.2)$ & 0 \\
\hline Atrial fibrillation & 0 & $1(0.1)$ \\
\hline Cardiac tamponade & 0 & $1(0.1)$ \\
\hline Hypertension & 0 & $1(0.1)$ \\
\hline Pericarditis & $1(0.2)$ & 0 \\
\hline Thromboangiitis obliterans & 0 & $1(0.1)$ \\
\hline Thrombosis & 0 & $1(0.1)$ \\
\hline Total patients $(\%)$ with $\geq 1 \mathrm{AE}$ infection & $223(39.1)$ & $353(40.3)$ \\
\hline \multicolumn{3}{|l|}{ Infections occurring in $\geq 2 \%$ of patients } \\
\hline Nasopharyngitis & $43(7.5)$ & $63(7.2)$ \\
\hline Upper respiratory tract infection & $37(6.5)$ & $64(7.3)$ \\
\hline Urinary tract infection & $31(5.4)$ & $31(3.5)$ \\
\hline Bronchitis & $19(3.3)$ & $27(3.1)$ \\
\hline Sinusitis & $20(3.5)$ & $25(2.9)$ \\
\hline Gastroenteritis & $14(2.5)$ & $12(1.4)$ \\
\hline Pharyngitis & $12(2.1)$ & $11(1.3)$ \\
\hline Total patients $(\%)$ with a serious infection & $9(1.6)$ & $15(1.7)$ \\
\hline Pneumonia & $2(0.4)$ & $2(0.2)$ \\
\hline Gastroenteritis & $2(0.4)$ & $1(0.1)$ \\
\hline Pyelonephritis & 0 & $3(0.3)$ \\
\hline Respiratory tract infection & $2(0.4)$ & 0 \\
\hline Abscess bacterial & $1(0.2)$ & 0 \\
\hline Abscess intestinal & $1(0.2)$ & 0 \\
\hline Bronchitis & 0 & $1(0.1)$ \\
\hline Bronchopneumonia & $1(0.2)$ & 0 \\
\hline Cellulitis & 0 & $1(0.1)$ \\
\hline Cellulitis gangrenous & 0 & $1(0.1)$ \\
\hline
\end{tabular}

SAE: serious adverse event.

was reported in a patient who had developed oropharyngeal cancer and received cancer chemotherapy and radiation. This event occurred about 18 months after the last dose of rituximab and 9 months after receiving chemotherapy and radiation.

Herpes zoster occurred in 49 patients (2\%) for a rate of 0.98 events per 100 pt-yrs. One of the 49 cases was an SAE that resolved, and the others were nonserious AE.

Immunoglobulin levels. Prior to receiving rituximab, 38 (1.5\%), $41(1.7 \%)$, and $18(0.7 \%)$ patients had $\operatorname{IgM}, \operatorname{IgG}$, and IgA levels below the laboratory LLN, respectively. Serum immunoglobulin levels, especially IgM, decreased during followup, with 602 (23\%) patients developing $\operatorname{IgM}<$ LLN on at least 1 visit at any time during post-baseline followup. A total of $141(5 \%)$ patients developed IgG < LLN on at least 1 visit, with $32(1 \%)$ of these patients with sus- tained IgG $<$ LLN for at least 1 year and 2 consecutive visits. Five patients had very low $\operatorname{IgG}$ levels $(<3 \mathrm{mg} / \mathrm{ml})$ and 14 patients $(<1 \%)$ had IgA levels $<$ LLN at any time. Median immunoglobulin levels remained > LLN over multiple treatment courses (Figure 3). There were no cases of undetectable immunoglobulin levels.

The proportion of patients with immunoglobulin levels $<$ LLN by course was also assessed. The proportion of patients with $\operatorname{IgM}<$ LLN at 6 months post-infusion increased by course. Following Course 1, 10\% of patients had IgM < LLN, vs $40 \%$ following Course 5 . Conversely, the proportion of patients with IgG $<$ LLN by course remained relatively stable, with 3\%-6\% < LLN; the proportion of patients with IgA < LLN remained very low and no different from baseline, at $<1 \%$.

Immunoglobulin levels and infections. SIE rates were similar before and after the detection of low IgM or IgG (Table 4). The sample size of patients with IgA was too small for meaningful infection analyses. The rates of SIE were numerically (but not significantly) greater following the development of low IgG at any time. Among the 32 patients with sustained low IgG, 6 patients experienced SIE; 10 of these 32 patients also had sustained low IgM, and 1 of these 10 patients experienced an SIE. Of potential predictors of serious infection, older age was the only independent predictor (HR 1.43 for every 10-years increased baseline age, $95 \%$ CI 1.24, 1.63, p < 0.001). Baseline immunoglobulin levels were not independent predictors of serious infection. $\operatorname{IgG}$ decreases were often transient, but some patients $(\mathrm{n}=$ 32) had sustained low IgG. Older age was also an independent predictor of sustained low $\operatorname{IgG}$ (HR 1.64 for every 10-years increased baseline age, 95\% CI 1.11, 2.43, p = $0.012)$. Among the 5 patients with very low $\operatorname{IgG}$ levels $(<3$ $\mathrm{mg} / \mathrm{ml}$ ), there were no serious infections.

Malignancies. The overall incidence of malignancies excluding nonmelanoma skin cancer was $0.84 / 100$ pt-yrs (42 patients, $1.6 \%$ ). The incidence rate was stable over multiple rituximab courses. No identifiable pattern of malignancies was observed. There was 1 case of lymphoma (Hodgkin's). The age- and sex-adjusted standardized incidence ratio (SIR) for malignancies, compared with the general population in the Surveillance, Epidemiology, and End Results database, was 1.05 (95\% CI 0.76, 1.42).

\section{DISCUSSION}

We describe safety data from an international rituximab RA clinical trial program in 2578 patients with 5013 pt-yrs of followup. This analysis represents the largest longitudinal safety report of rituximab in RA to date and greatly increases the power to detect common and rare safety risks compared with a more recent report of 1600 pt-yrs of followup $^{13}$. Rituximab was generally well tolerated over multiple courses, consistent with previous smaller studies $^{11,12,15}$, and the risk of SAE, including serious infections Personal non-commercial use only. The Journal of Rheumatology Copyright (C 2010. All rights reserved. 


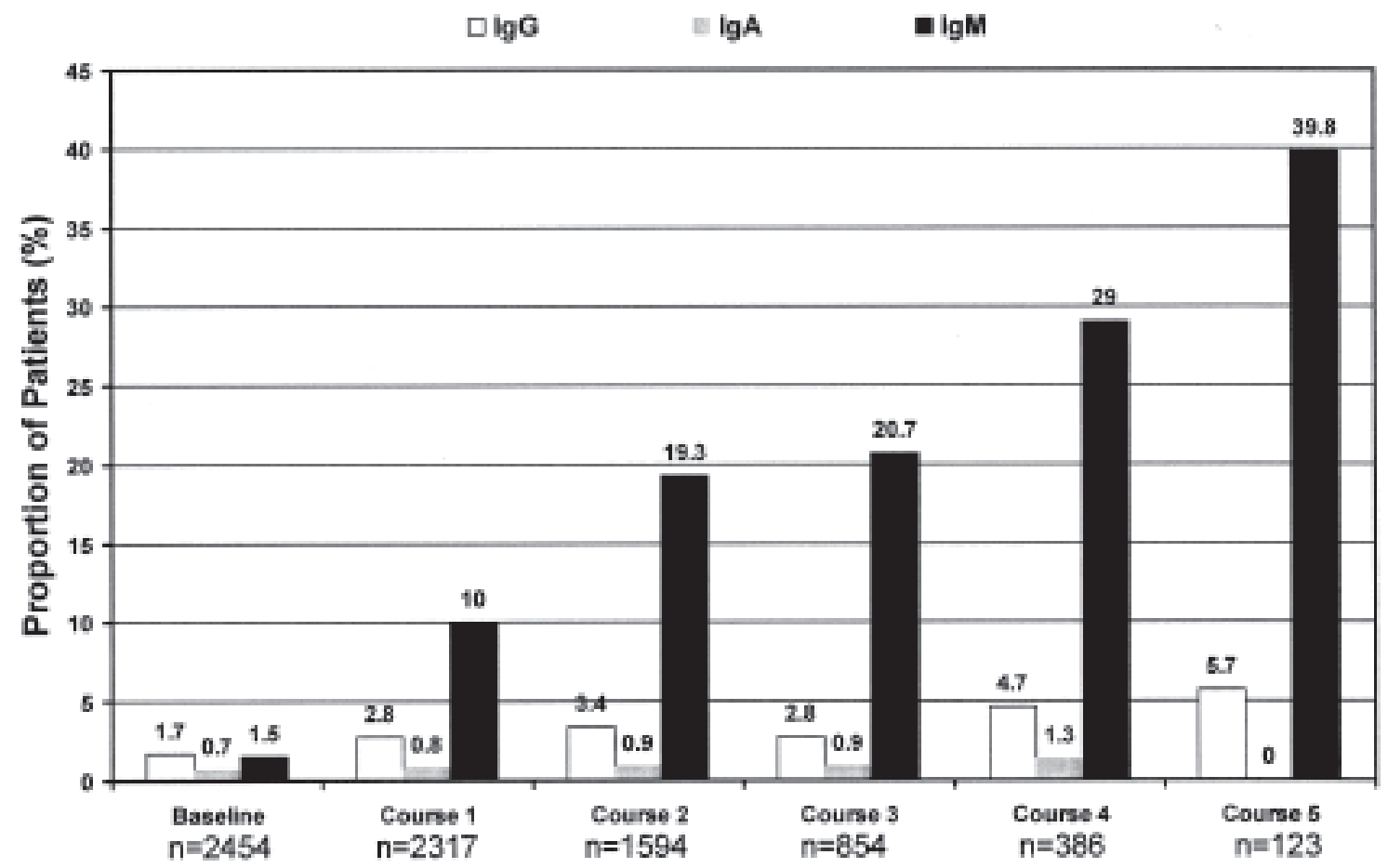

B
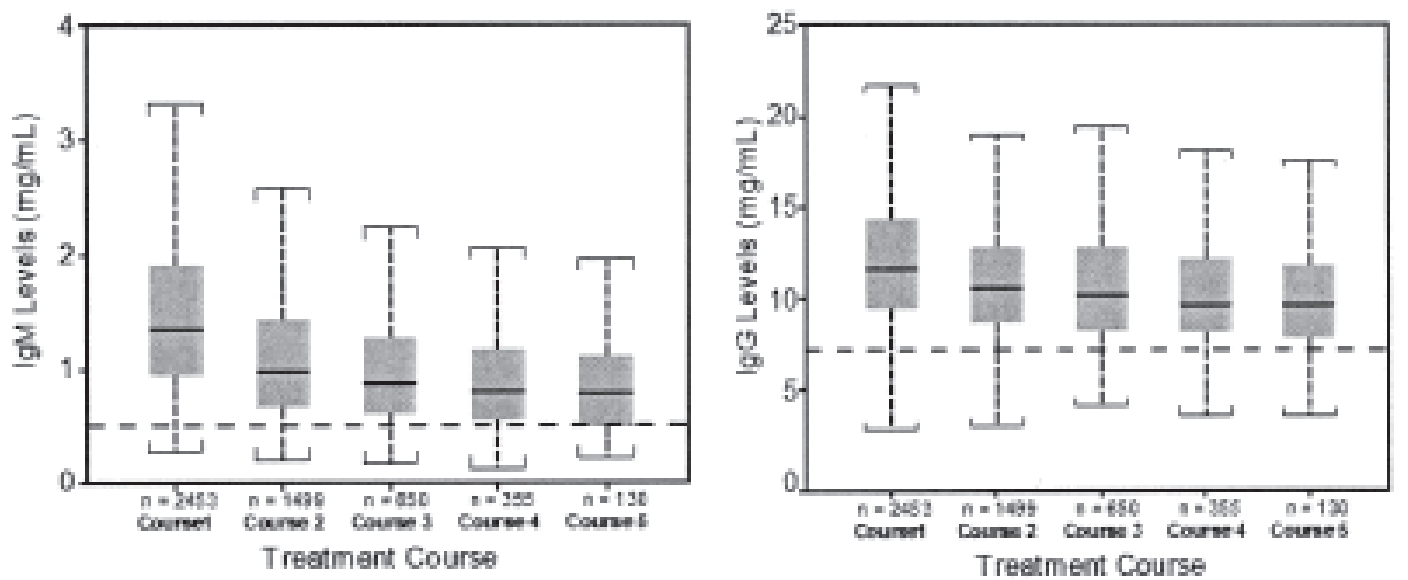

Figure 3. A. Proportion of patients with immunoglobulin levels $<$ the lower limit of normal (LLN) 6 months following each course. Proportions of patients with IgG (LLN 5.2-6.7 mg/ml), IgM (LLN $0.5 \mathrm{mg} / \mathrm{ml}$ ), and IgA (LLN $0.5 \mathrm{mg} / \mathrm{ml})$ levels < LLN are shown at baseline and after Courses 1 to 5. B. IgM and IgG over treatment courses [medians and interquartile ranges (IQR) shown]. Values represented are median values (solid line), the edges of the boxes are the first and third quartiles (box represents IQR), and the error bars (broken vertical lines) are calculated as $1.5 \times$ IQR from the median. Broken horizontal lines are LLN for IgM $(0.5 \mathrm{mg} / \mathrm{ml}) \mathrm{and}$ $\operatorname{IgG}(6.7 \mathrm{mg} / \mathrm{ml})$.

and infusion reactions, was not increased by treatment course or overall time of exposure to rituximab.

Although patients may have received up to 10 courses of rituximab, only patients who received up to 5 courses were evaluated per course because the numbers of patients who received $>5$ courses were small and point estimates of rates had wide CI. The patients enrolled in the trials studied had active, longstanding disease, about half the patients having previously received treatment with TNF inhibitor(s).

The most common AE were infusion-related reactions (IRR). The rates of IRR decreased over successive courses of rituximab, and were more common with the first infusion of each course compared to the second infusion. This pattern is consistent with the hypothesis that cytokine release syn- 
Table 4. Rate of serious infections prior to and after immunoglobulin levels below the lower limit of normal (LLN) on at least 1 occasion. Multiple occurrences of the same event in 1 patient are counted multiple times. LLN was 5.2 to $6.7 \mathrm{mg} / \mathrm{ml}$ for immunoglobulin $\mathrm{G}(\mathrm{IgG})$ and $0.5 \mathrm{mg} / \mathrm{ml}$ for immunoglobulin $\mathrm{M}$ (IgM), depending on the laboratory.

\begin{tabular}{|c|c|c|c|c|c|c|}
\hline & \multicolumn{2}{|c|}{$\begin{array}{c}\text { Patients with } \\
\text { IgG }<\text { LLN } \\
n=141\end{array}$} & \multicolumn{2}{|c|}{$\begin{array}{c}\text { Patients with } \\
\operatorname{IgM}<\mathrm{LLN} \\
\mathrm{n}=602\end{array}$} & \multirow{2}{*}{$\begin{array}{l}\text { Patients with } \\
\text { IgM > LLN at } \\
\text { All Times, } \\
\text { n = } 1803 \\
\text { Anytime }\end{array}$} & \multirow{2}{*}{$\begin{array}{c}\text { All Exposure } \\
\text { Population, } \\
\mathrm{n}=2578 \\
\text { Anytime }\end{array}$} \\
\hline & Before & After & Before & After & & \\
\hline Total patient-yrs & 156.88 & 212.58 & 607.05 & 781.01 & 3305.47 & 5013.50 \\
\hline No. of serious infections & 10 & 18 & 22 & 36 & 137 & 216 \\
\hline $\begin{array}{l}\text { No. of serious infections per } \\
100 \text { patient-years }\end{array}$ & 6.37 & 8.47 & 3.62 & 4.61 & 4.14 & 4.31 \\
\hline $95 \% \mathrm{CI}$ & $3.43,11.85$ & $5.33,13.44$ & $2.39,5.50$ & $3.32,6.39$ & $3.51,4.90$ & $3.77,4.92$ \\
\hline
\end{tabular}

drome is less likely with additional courses because of a lower B cell load.

The overall rate of serious infection was 4.31 infections per 100 pt-yrs (95\% CI 3.77, 4.92), and is in the range of other RA biologics. In a longterm followup of etanercept, a rate of 4.2 events per 100 pt-yrs (range 2.9-5.8 serious infections per $100 \mathrm{pt}$-yrs) across 8 years of followup was reported $^{22}$. Similarly, adalimumab showed a rate of 5.1 seri-

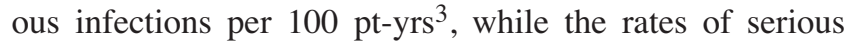
infection reported for abatacept have ranged from 4.2 to 5.3 events per $100 \mathrm{pt}-\mathrm{yrs}$ in longterm followup analyses ${ }^{23,24}$. Importantly, there were no notable differences in serious infections between rituximab and placebo during placebo-controlled observation periods.

Viral reactivation is a potential concern in immunosuppressed patients. The rate of herpes zoster infections $(0.98$ events per 100 pt-yrs) was similar to that reported for other RA populations. Among patients with RA enrolled in the National Data Bank for Rheumatic Diseases study, the incidence of herpes zoster was 1.32 per 100 pt-yrs ${ }^{25}$. Among patients with RA, in both the General Practice Research Database and the PharMetrics healthcare claims database, the incidence of herpes zoster ranged from 1.06 to 0.98 per $100 \mathrm{pt}-\mathrm{yrs}^{26}$. The much more serious and rare opportunistic infection PML, caused by reactivation of the JC virus, occurred in a patient who also received cancer chemotherapy. PML has also been reported in patients with autoimmune diseases other than RA, who had received other immunosuppressive therapies with or without rituximab ${ }^{27,28}$. The effect of rituximab treatment in relation to PML remains unclear, although patients with systemic lupus erythematosus (SLE) may be predisposed to PML and in 2 cases of patients with SLE who were treated with rituximab, PML was reported ${ }^{29}$.

Average IgM levels decreased with multiple courses of rituximab, but this did not appear to be associated with an increased rate of serious infection. Decreases in IgM levels may be due to the presence of IgM on plasmablasts contain- ing $\mathrm{CD} 20^{30}$. Levels of $\operatorname{IgG}$ and $\operatorname{Ig} \mathrm{A}$ also decreased in some patients, but to a minimal degree compared with changes in $\mathrm{IgM}$. Sustained low IgG levels were rare, occurring in $1 \%$ of patients. Classical observations have shown that $\mathrm{IgG}$ is the most important among serum immunoglobulins for protective immunity and that patients with low levels of IgG are at increased risk of serious infections ${ }^{31}$. Among patients with low IgG levels at any time, there was a nonsignificant trend toward higher rates of serious infections occurring at variable times from the measurement of low $\mathrm{IgG}$.

Certain factors may lead to decreases in $\operatorname{IgG}$ levels, including older age and concomitant steroid use. Indeed, in placebo-controlled studies, decreases in IgG levels were also seen in placebo-treated patients who received corticosteroids. In studies of rituximab for multiple sclerosis, IgG levels appeared stable where concomitant corticosteroids were not used ${ }^{32,33}$. In our analysis, older age was most strongly predictive of sustained low IgG levels. Older patients are known to be at increased risk of infection and waning humoral immunity ${ }^{34}$. Given concomitant corticosteroid use in the clinical trials, the contribution of rituximab treatment to the development of low IgG in some patients is not clear. Irrespective of the underlying mechanisms for patients who had low IgG levels, this subset of patients may be at higher risk for infections and should be monitored closely.

There were no notable differences in serious cardiovascular events during placebo-controlled periods. In the longer-term analyses, MI was one of the most common SAE reported, occurring at a rate of 0.56 per 100 pt-yrs. This is expected, given that patients with RA are at increased risk of cardiovascular disease ${ }^{8,9}$. The rate of MI observed is consistent with rates reported in epidemiologic studies of patients with RA. The British Society for Rheumatology Biologics Registry reported a rate of MI of 0.48 per 100 pt-yrs for patients treated with TNF inhibitors and 0.59 per 100 pt-yrs for patients treated with traditional DMARD ${ }^{35}$. The British Columbia Claims Database reported an MI rate of 0.53 per

Personal non-commercial use only. The Journal of Rheumatology Copyright $\subset$ (c) 2010. All rights reserved. 
100 pt-yrs in patients with $\mathrm{RA}^{36}$. There was no evidence for an increased association between MI and rituximab treatment in patients with RA.

The types of malignancies observed were variable. Only 1 lymphoma was reported, although lymphomas have been shown to have a higher incidence in patients with RA as compared with the general population ${ }^{37,38}$. The age- and sex-adjusted standardized incidence ratio (SIR) for malignancies among patients treated with rituximab was 1.05 $(95 \%$ CI $0.76,1.42)$. The SIR of rituximab falls within the range of results reported in 4 similar analyses (SIR estimates: 1.0,1.1, 1.2,1.52) comparing the incidence of malignancies among patients with RA to that of general populations ${ }^{39}$, and a US study found the rate of physician-determined malignancies was 1.30 per 100 pt-yrs (95\% CI 1.19, $1.41)^{38}$. These data indicate that patients with RA treated with rituximab were not at an increased risk of malignancy compared with other patients with RA and the general US population.

The mortality rate observed was 0.6 per 100 pt-yrs, with a SMR of 0.83 (95\% CI $0.56,1.18)$, indicating no difference in mortality between rituximab-treated patients with RA in clinical trials and the general US population ${ }^{13,21,22,40}$.

There are some potential limitations in the approaches used for our analysis. We pooled information from diverse controlled studies in which re-treatment, active disease status, and rituximab doses could differ. Longterm followup data from patients originally recruited for a randomized clinical trial are constrained by the inclusion and exclusion criteria used in the specific trials. Clinical trial data of this type are also, by necessity, derived from study completers, although in this analysis the population included both patients who had initially been randomized to rituximab and patients who had a positive result (and were therefore motivated to continue), and also patients who did not respond after initial treatment with rituximab or placebo and were therefore motivated to use rituximab in an open-label study. Moreover, withdrawal due to $\mathrm{AE}$ was low (5\%). Because 2 of the studies were limited to patients receiving 1 or 2 courses of rituximab per protocol, the number of patients eligible for Course 3 and beyond was more limited than for Courses 1 and 2 (although still over 1000 patients). Strengths of this study include longterm followup with frequent assessments in a population of patients with advanced RA.

In patients with RA treated with rituximab, the longterm safety profile in selected clinical trial populations was consistent with observations from placebo-controlled clinical trials. Over 5 courses of rituximab treatment, serious adverse events, including serious infection and infusion reactions, did not increase over time.

\section{ACKNOWLEDGMENT}

We acknowledge the patients and physicians who participated in all studies. Keith Del Villar, PhD, provided writing assistance that was supported by Genentech Inc., Biogen Idec, and F. Hoffmann La Roche Ltd.

\section{REFERENCES}

1. Genovese MC, Bathon JM, Fleischmann RM, Moreland LW, Martin RW, Whitmore JB, et al. Longterm safety, efficacy, and radiographic outcome with etanercept treatment in patients with early rheumatoid arthritis. J Rheumatol 2005;32:1232-42.

2. Maini RN, Breedveld FC, Kalden JR, Smolen JS, Furst D, Weisman MH, et al. Sustained improvement over two years in physical function, structural damage, and signs and symptoms among patients with rheumatoid arthritis treated with infliximab and methotrexate. Arthritis Rheum 2004;50:1051.

3. Schiff MH, Burmester GR, Kent JD, Pangan AL, Kupper H, Fitzpatrick SB, et al. Safety analyses of adalimumab (HUMIRA) in global clinical trials and US postmarketing surveillance of patients with rheumatoid arthritis. Ann Rheum Dis 2006;65:889-94.

4. Fleischmann RM. Safety of biologic therapy in rheumatoid arthritis and other autoimmune diseases: focus on rituximab. Semin Arthritis Rheum 2009;38:265-80.

5. Bongartz T, Sutton AJ, Sweeting MJ, Buchan I, Matteson EL, Montori V. Anti-TNF antibody therapy in rheumatoid arthritis and the risk of serious infections and malignancies: systematic review and meta-analysis of rare harmful effects in randomized controlled trials. JAMA 2006;295:2275-85.

6. Kroesen S, Widmer AF, Tyndall A, Hasler P. Serious bacterial infections in patients with rheumatoid arthritis under anti-TNF-alpha therapy. Rheumatology 2003;42:617-21.

7. Baecklund E, Iliadou A, Askling J, Ekbom A, Backlin C, Granath F, et al. Association of chronic inflammation, not its treatment, with increased lymphoma risk in rheumatoid arthritis. Arthritis Rheum 2006;54:692-701.

8. Wolfe F, Michaud K. Heart failure in rheumatoid arthritis: rates, predictors, and the effect of anti-tumor necrosis factor therapy. Am J Med 2004;116:305-11.

9. Khan AH, Spodick DH. Rheumatoid heart disease. Semin Arthritis Rheum 1972;1:327-37.

10. Maloney DG, Grillo-López AJ, White CA, Bodkin D, Schilder RJ, Neidhart JA, et al. IDEC-C2B8 (Rituximab) anti-CD20 monoclonal antibody therapy in patients with relapsed low-grade nonHodgkin's lymphoma. Blood 1997;90:2188-95.

11. Cohen SB, Emery P, Greenwald MW, Dougados M, Furie RA, Genovese MC, et al. Rituximab for rheumatoid arthritis refractory to anti-tumor necrosis factor therapy: Results of a multicenter, randomized, double-blind, placebo-controlled, phase III trial evaluating primary efficacy and safety at twenty-four weeks. Arthritis Rheum 2006;54:2793-806.

12. Emery P, Fleischmann R, Filipowicz-Sosnowska A, Schechtman J, Szczepanski L, Kavanaugh A, et al. The efficacy and safety of rituximab in patients with active rheumatoid arthritis despite methotrexate treatment: results of a phase IIB randomized, double-blind, placebo-controlled, dose-ranging trial. Arthritis Rheum 2006;54:1390-400.

13. Keystone E, Fleischmann R, Emery P, Furst DE, van Vollenhoven $\mathrm{R}$, Bathon J, et al. Safety and efficacy of additional courses of rituximab in patients with active rheumatoid arthritis: an open-label extension analysis. Arthritis Rheum 2007;56:3896-908.

14. Sell S, Max EE. All about B cells. In: Immunology, immunopathology, and immunity. Herndon, VA: ASM Press; 2001:101.

15. Edwards JC, Szczepanski L, Szechinski J, Filipowicz-Sosnowska A, Emery P, Close DR, et al. Efficacy of B-cell-targeted therapy with rituximab in patients with rheumatoid arthritis. N Engl J Med 2004;350:2572-81.

16. Emery P, Rigby WF, Combe B, Latinis K, Szczepanski LJ, Roschmann RA, et al. Efficacy and safety of rituximab (RTX) as first line biologic therapy in patients with active rheumatoid arthritis. Results of a phase III randomized, controlled study 
(SERENE) [abstract]. Arthritis Rheum 2008;Suppl 58:S302 .

17. Rubbert-Roth A, Tak PP, Bombardieri S, Zerbini C, Tremblay $\mathrm{J}$, Carreño L, et al. Efficacy and safety of various dosing regimens of rituximab in patients with active RA: results of a phase III randomized study (MIRROR) [abstract]. Arthritis Rheum 2008;Suppl 58:S301.

18. Mease PJ, Cohen S, Gaylis NB, Chubick A, Kaell AT, Greenwald $\mathrm{M}$, et al. Efficacy, safety, and dose frequency of retreatment with rituximab in RA: results from a randomized controlled trial (SUNRISE) [abstract]. Arthritis Rheum 2008;Suppl 58:S619.

19. Bingham C, Looney R, Deodhar A, Halsey N, Greenwald M, Codding $\mathrm{C}$, et al. Results from a controlled clinical trial (SIERRA) to evaluate primary and recall responses to immunizations in RA patients treated with rituximab [abstract]. Arthritis Rheum 2008;Suppl 58:S900.

20. Keystone EC, Fleischmann R, Emery P, Chubick A, Dougados MR, Baldassare AR, et al. Efficacy and safety of repeat treatment courses of rituximab (RTX) in RA patients with inadequate response to tumor necrosis factor inhibitors; long-term experience from the REFLEX study [abstract]. Arthritis Rheum 2008;Suppl 58:S303.

21. Centers for Disease Control/National Center for Health Statistics. National Vital Statistics Reports. Deaths: Final data for 2005. [Internet. Accessed Dec 10, 2009.] Available from: http://www.cdc.gov/nchs/data/nvsr/nvsr56/nvsr56_10.pdf

22. Moreland LW, Weinblatt ME, Keystone EC, Kremer JM, Martin $\mathrm{RW}$, Schiff MH, et al. Etanercept treatment in adults with established rheumatoid arthritis: 7 years of clinical experience. J Rheumatol 2006;33:854-61.

23. Genovese MC, Schiff M, Luggen M, Becker JC, Aranda R, Teng $\mathrm{J}$, et al. Efficacy and safety of the selective co-stimulation modulator abatacept following 2 years of treatment in patients with rheumatoid arthritis and an inadequate response to anti-tumour necrosis factor therapy. Ann Rheum Dis 2008;67:547-54.

24. Kremer JM, Genant HK, Moreland LW, Russell AS, Emery P, Abud-Mendoza C, et al. Results of a two-year followup study of patients with rheumatoid arthritis who received a combination of abatacept and methotrexate. Arthritis Rheum 2008;58:953-63.

25. Wolfe F, Michaud K, Chakravarty EF. Rates and predictors of herpes zoster in patients with rheumatoid arthritis and non-inflammatory musculoskeletal disorders. Rheumatology 2006;45:1370-5.

26. Smitten AL, Choi HK, Hochberg MC, Suissa S, Simon TA, Testa MA, et al. The risk of herpes zoster in patients with rheumatoid arthritis in the United States and the United Kingdom. Arthritis Rheum 2007;57:1431-8.

27. Aksamit AJ. Progressive multifocal leukoencephalopathy. Curr Treat Options Neurol 2008;10:178-85.

28. Rahmlow M, Shuster EA, Dominik J, Deen HG Jr, Dickson DW, Aksamit AJ Jr, et al. Leflunomide-associated progressive multifocal leukoencephalopathy. Arch Neurol 2008;65:1538-9.
29. Molloy ES, Calabrese LH. Progressive multifocal leukoencephalopathy in patients with rheumatic diseases: are patients with systemic lupus erythematosus at particular risk? Autoimmun Rev 2008;8:144-6.

30. Teng YK, Levarht EW, Hashemi M, Bajema IM, Toes RE, Huizinga TW, et al. Immunohistochemical analysis as a means to predict responsiveness to rituximab treatment. Arthritis Rheum 2007:56:3909-18

31. Bonilla FA, Bernstein IL, Khan DA, Ballas ZK, Chinen J, Frank MM, et al. Practice parameter for the diagnosis and management of primary immunodeficiency. Ann Allergy Asthma Immunol 2005;94(5 Suppl 1):S1-63.

32. Hauser SL, Waubant E, Arnold DL, Vollmer T, Antel J, Fox RJ, et al. B-cell depletion with rituximab in relapsing-remitting multiple sclerosis. N Engl J Med 2008;358:676-88.

33. Bar-Or A, Calabresi PA, Arnold D, Markowitz C, Shafer S, Kasper $\mathrm{LH}$, et al. Rituximab in relapsing-remitting multiple sclerosis: a 72-week, open-label, phase I trial. Ann Neurol 2008;63:395-400.

34. Burns EA, Lum LG, L'Hommedieu G, Goodwin JS. Specific humoral immunity in the elderly: in vivo and in vitro response to vaccination. J Gerontol 1993;48:B231-6.

35. Dixon WG, Watson KD, Lunt M, Hyrich KL, British Society for Rheumatology Biologics Register Control Centre Consortium. Reduction in the incidence of myocardial infarction in patients with rheumatoid arthritis who respond to anti-tumor necrosis factor alpha therapy: results from the British Society for Rheumatology Biologics Register. Arthritis Rheum 2007;56:2905-12.

36. Solomon DH, Goodson NJ, Katz JN, Weinblatt ME, Avorn J, Setoguchi S, et al. Patterns of cardiovascular risk in rheumatoid arthritis. Ann Rheum Dis 2006;65:1608-12.

37. Mellemkjaer L, Linet MS, Gridley G, Frisch M, Møller M, Olsen $\mathrm{JH}$. Rheumatoid arthritis and cancer risk. Eur J Cancer 1996;32A:1753-7.

38. Wolfe F, Michaud K. The effect of methotrexate and anti-tumor necrosis factor therapy on the risk of lymphoma in rheumatoid arthritis in 19,562 patients during 89,710 person-years of observation. Arthritis Rheum 2007;56:1433-9.

39. Smitten AL, Simon TA, Hochberg MC, Suissa S. A meta-analysis of the incidence of malignancy in adult patients with rheumatoid arthritis. Arthritis Res Ther 2008;10:R45.

40. Burmester GR, Mariette X, Montecucco C, Monteagudo-Sáez I, Malaise M, Tzioufas AG, et al. Adalimumab alone and in combination with disease-modifying antirheumatic drugs for the treatment of rheumatoid arthritis in clinical practice: the Research in Active Rheumatoid Arthritis (ReAct) trial. Ann Rheum Dis 2007;66:732-9. 